Firstly, new products derived from biotechnology will be assessed and approved by a centralised organisation. The procedure agreed by the Community will be compulsory for biological innovations, but it will also be available-at the choice of the company - for any new chemical entities whether or not derived from bioengineering methods. The current system of national regulatory agencies will continue to function, however, and this procedure will be available for the approval of conventional drugs.

The second proposal is that companies that have been given authorisation for a drug in one home country will be able to apply to other member states for them to accept this decision. The intention is that there will be autorecognition of agreements for marketing approval. If a country has doubts about accepting an authorisation of this kind (and one that cannot be resolved by discussions among the national regulatory agencies) then arbitration resulting in a binding decision will be arranged at the level of the Community.

Thirdly, it will remain possible after 1992 for small companies intending to market products only in their home country to apply for solely national registration.
This proposed three level system of regulation will require creating a central regulatory structure - a European medicines agency with committees for human and veterinary products, specialist working parties, and arbitration procedures. Decisions of the agency should be binding on member states - both its central regulatory procedures and its arbitration tasks. The agency is also expected to coordinate the existing national monitoring procedures for adverse drug reactions and for inspecting the manufacture of drugs and testing their quality.

At present these proposals are being discussed by European Community member states. ${ }^{1}$ The creation of a medicines agency whose decisions will be binding seems likely to provoke some controversy, but once agreed it will provide the framework for steady progress towards European unity on drugs - at least in terms of their scientific evaluation.

Deputy Editor, $B M \mathcal{F}$

TONY SMITH

1 The European Commission. Future system for the authorisation of medicinal products with the European Community. A discussion document. Brussels: European Commission, 1989. (III/8267/89 Revision 2.)

\title{
Infectious disease control
}

\section{A review of the law offers an opportunity to aid the revival of British public health}

One of the problems identified by the Acheson report, Public Health in England, was confusion about responsibility for the control of communicable diseases, including poor communication between some local and health authorities and dissatisfaction with the role of the medical officer for environmental health. ${ }^{1}$ Along with other aspects of the report some of these deficiencies have already been tackled-for example, by appointing consultants in communicable disease control. ${ }^{2}$ But the Acheson committee also pointed out the need for a review of the law on infectious disease, and the Department of Health has now responded with a consultation document. ${ }^{3}$

The key question the document poses is whether district health authorities or local authorities, or both, should have the statutory duty to provide, lead, and coordinate an infectious disease control service. ${ }^{3}$ The answer must surely be that both should, district health authorities being responsible for surveillance, investigation, control, and prevention of disease ("matters affecting persons") and local authorities being responsible for surveillance, investigation, and control of environmental hazards ("matters relating to the environment"). This clarification of responsibilities should enhance the close working relationships between medical officers for environmental health and chief environmental health officers that exist in most districts, as should the greater specialist training given to the consultants in communicable disease control than the medical officers for environmental health received in the past. Every infectious disease has an environmental component, most notably in food borne and waterborne disease, and many environmental hazards are related to infection. So consultants and chief environmental health officers would be helped to do their job if district health authorities and local authorities had a statutory requirement to provide support for each other-for example, by deploying staff when necessary. An honorary appointment of the consultants in communicable disease control to the appropriate local authorities and of the chief environmental health officer to the corresponding health authorities would help, especially if the concept of the "proper officer" to local authorities were discontinued.

If control of infection in people is to become a health authority responsibility it follows that statutory notification of infectious disease should be to district health authorities and that they should have the legal powers to deal with it. In practice, notifications should be sent in strict confidence to the consultants in communicable disease control, as the Acheson report suggested; indeed, this currently happens informally in some parts of England and Wales. The legal powers available to the consultants in communicable disease control should include exclusion from work or school, isolation of people at home or in hospital, compulsory medical examination, and entry to premises for investigating and controlling infection. Obtaining epidemiological information from individual people, either during investigation of an episode of infection or as part of an epidemiological survey, does not usually require legal powers, although occasionally these might be helpful. Most existing public health law is concerned with environmental control and is therefore a local authority function. Similarly, food law, including the lay reporting of gastrointestinal infections from food premises, should continue to be a local authority responsibility.

The consultation document describes the complexity of current legislation on statutorily notifiable infectious disease, which could be simplified by limiting the number of notifiable diseases and applying the same set of regulations to all of them. ${ }^{3}$ Notification should be confined to those diseases that require urgent control measures or for which legal powers might be required and those for which preventive programmes, such as immunisation, are in progress or likely to begin soon. The consultation document suggests two lists: one of diseases for immediate action and the other of those for surveillance. But two lists would cause confusion, and a single list with internationally accepted case definitions would be preferable. Some of the existing 29 notifiable diseases could be 
deleted and surveillance maintained by other systems - for example, through general practitioner reporting in the Royal College of General Practitioners Birmingham research unit scheme, laboratory reporting by medical microbiologists of data collected in England and Wales by the Public Health Laboratory Service Communicable Disease Surveillance Centre, local hospital and clinic reports, and special surveillance schemes. Other diseases could be included, such as legionnaires' disease, ornithosis, and Q fever, because these may need immediate preventive action.

Notification should remain the clinician's responsibility. It should be made on suspicion of the diagnosis and within 48 hours on a modernised form or by electronic means, although clinicians should telephone the consultant in communicable disease control if immediate investigation and control measures are required. The substantial increase in the fee in 1984 did not seem to encourage more complete notification, ${ }^{+}$ the system is costly to administer, and it could be argued that notification is part of a clinician's duty to the public health. If the fee were replaced by regular provision of information to clinicians on prevalent infections and control measures then such feedback would be more likely to improve the ascertain- ment, encourage notification, and lead to more effective prevention. Prosecution for failure to notify is not appropriate, and these regulations should be repealed. If it ever occurred, deliberate concealment of a notifiable disease should be a medical disciplinary matter.

The present functions of port health authorities are also discussed in the consultation document, which asks whether these should be absorbed into local authorities and district health authorities. ${ }^{2}$ The logical answer is yes, if only to reduce the multiplicity of authorities and simplify local public health action. Local authorities should assume the environmental functions and district health authorities the functions affecting people.

N S GALBRAITH

London SE3 8BS

Consultant Epidemiologist

\footnotetext{
Committee of Inquiry into the Future of the Public Health Function. Public health in England. Report. London: HMSO, 1988. (Cmnd 289.)

2 Department of Health. Health of the population: responsibilities of health authorities. London: $\mathrm{DoH}$ 1988. ( $\mathrm{HC}(88) 64$.)

3 Department of Health. Review of law on infectious disease control. Consultation document. London: $\mathrm{DoH}, 1989$.

$4 \mathrm{McCormick}$ A. Notification of infectious diseases: the effect of increasing the fee paid. Health Trends $1987 ; 19: 7-8$
}

\section{Nurses: the point of no return}

\section{Abandon the model of unbroken full time service, or there will be no more nurses}

A tenth of qualified nurses and a quarter of nursing students leave the NHS every year. Meanwhile the pool of 18 year olds - from which nurse recruits are traditionally drawn-is shrinking fast. If the status quo continues future patients will pay a heavy price for the absence of skilled care. How are the profession and the service responding to this alarming prospect?

Trench warfare and workforce planning for nurses may not seem to have much in common, but Haig-style tactics have been the norm: recruits who were mown down or retired hurt (or pregnant) were replaced by fresh volunteers. This pragmatism was never beneficial to patients or staff, and it will soon cease to be an option. Society's need for skilled workers is creating attractive alternative careers for potential recruits as well as for nursing veterans. Until the NHS devises a new plan of campaign female staff will continue to leave in droves-and its workforce problems will prove more catastrophic than any amount of misguided reform.

The challenge to managers is simple: keep qualified nurses in the NHS, and tempt back the thousands who have left. As $90 \%$ of nurses are women and many have children, the "male model" of unbroken full time service must be abandoned in favour of practices that help the working woman to manage her double shift of home and job. The necessary measures, also vital to retain women doctors and other professional staff, include schemes for keeping in touch and returning to practice; flexible working patterns; and part time posts that are not career cul de sacs.

Outlining the challenges may be simple, but the solutions are complex, especially as success will depend on overturning decades of rigid attitudes and routines. The Department of Health, the nursing unions, and the regulatory nursing bodies are pushing for such measures, and enlightened health authorities are running back to nursing courses, opening crèches, and experimenting with flexitime. Yet these initiatives are still patchy and of variable quality; they may be too little and too late.

More positive attitudes to women workers on the part of the government would help. The NHS is the biggest employer of women in Europe, yet Britain lags behind most of its continental neighbours in the help it gives with child care. A more concerted effort is also needed from the Department of Health and the nursing bodies to build on current good practice, allocating funds and expertise to share and develop useful ideas.

Primarily, though, the battle will be won or lost at the grass roots. Given the right support and encouragement from local managers, hospital and community sisters and charge nurses can and do create environments that enable nurses with children or elderly or disabled dependents to work flexible hours with no loss of job satisfaction or professional development. The problem is that most nurses, let alone doctors or managers, have yet to rethink their own attitudes or grasp the full implications of flexibility. Dispensing with ritual morning reports or fixed ward rounds (which is beginning to occur as routines are reorganised around the needs of patients rather than staff) will not be easy. The cost of failure, however, will be huge. Whom would you rather have nursing you next time you need care: an expert nurse, or an untrained support worker?

JANE SALVAGE

Director, Nursing Developments,

King's Fund Centre for Health Services Development, London NW1 7NE 